\title{
Pandemia de Covid-19 e destruição da natureza: uma crítica baseada no marxismo ecológico
}

\author{
Covid-19 pandemic and destruction of nature: a critique based on ecological \\ Marxism
}

\section{Magno da Conceição Peneluc ${ }^{*}$}

Resumo: A relação que o ser humano concretiza com a natureza por meio do trabalho é a premissa ontológica fundante do marxismo ecológico. As relações de produção, a precarização do trabalho e a luta de classes encontram-se dialeticamente relacionados com a degradação ambiental, pois o sistema produtivo utiliza-se do trabalho humano e da natureza como meios de produção, levando a impactos socioambientais que podem limitar a produção. Neste cenário de degradação da natureza e de precarização do trabalho, como uma pandemia pode evoluir historicamente?

Palavras-chave: Dialética; Falha metabólica; Espiral de destruição ecológica; Saúde pública

Abstract: The relationship that human beings establish with nature through work is the founding ontological premise of ecological Marxism. The relations of production, the precariousness of work and the class struggle are dialectically related to environmental degradation, because the productive system uses human labor and nature as means of production, leading to socio-environmental impacts that can limit production. In this scenario of degradation of nature and precarious work, how can a pandemic evolve historically?

Keywords: Dialectic; Metabolic failure; Spiral of ecological destruction; Public health

\section{Marxismo ecológico e o metabolismo entre a sociedade e a natureza}

As relações que os seres humanos realizam com a natureza é o ponto de partida para a concepção da ontologia do ser social construída por Karl Marx. Para o marxismo ecológico é fundamental a noção ontológica do trabalho como mediador primordial entre o ser humano e a natureza.

A Ecologia elucidou a relevância da ciclagem de nutrientes e o fluxo de energia com base no conceito de metabolismo dos sistemas ecológicos. Eugene P. Odum, assim como Marx, se embasou nas pesquisas Justus von Liebig, que criticou a agricultura industrial britânica no final dos anos $180^{1}$. Desse contexto deriva a noção central da relação entre inorgânico e orgânico, fundamento primaz ao conceito de ecossistema, desenvolvido por Arthur Tansley, em 1935.

Marx introduziu o conceito de "metabolismo social", que desde o início dos anos 1860 ocupou um lugar central em toda a sua obra econômica. O livro de 1926, A Biosfera, de V. I. Vernadsky, também de grande importância ao marxismo ecológico, onde argumenta que a interação dos seres vivos com o ambiente físico-geológico altera os ecossistemas de maneira

${ }^{1}$ FOSTER, Marxismo e ecologia: fontes comuns de uma grande transição, p. 83.

* Doutor em Filosofia pela Universidade Federal da Bahia, Salvador, BA. E-mail: bio.magno@gmail.com ORCID: https://orcid.org/o000-0001-6015-0295 
global. Em 1944, Karl Polanyi publicou outra obra relevante, The Great Transformation, na qual debate o crescimento do capitalismo e as consequências destrutivas ao meio ambiente ${ }^{2}$.

A constituição do ser social foi descrita por Marx como uma conexão entre três tipos diferentes de ser: o ser da natureza inorgânica, o ser da natureza orgânica e o ser da sociedade. O ser social é constituído por três seres indistintamente entrelaçados, mas com uma dinâmica, um movimento que distingue o ser social: a prévia-ideação, que conduz ao pôr teleológico definidor da intencionalidade imediata viabilizada pela práxis. Por teleológico é uma categoria que se refere às mediações que o homem faz com a natureza por meio do trabalho (por teleológico primário), as mediações realizadas entre os seres humanos (política, ideologia, educação, por exemplo), constituem os pores teleológicos secundários) ${ }^{3}$.

A dialética ser humano/natureza pensada de forma histórica foi o que tornou possível que Marx constituísse sua concepção de ser humano, a partir da qual fundamentou sua crítica à economia política.

O homem ao produzir só pode atuar como a própria natureza, isto é, mudando as formas da matéria. Neste trabalho de transformação é constantemente ajudado pelas forças naturais. O trabalho não é, por conseguinte, a única fonte de valores de uso que produz da riqueza material. Conforme diz William Petty, o trabalho é o pai, mas a terra é a mãe4.

Dessa forma, o ambiente é o resultado das recíprocas relações entre sociedade e natureza num dado espaço e tempo concreto. É a expressão do nosso sociometabolismo, é a síntese da relação homem/natureza ao longo da história social. O nexo dialético entre o trabalho e a natureza concretiza-se, concomitantemente, como meio de produção, fonte de valores de uso e objetos de trabalho. Numa condição de mútua reciprocidade, a natureza condiciona o trabalho e este, por sua vez, a modifica com determinados fins. A natureza é fonte material das riquezas e o trabalho é dotado de riquezas específicas, mas não de toda a riqueza material. A natureza natural e histórica do ser humano constitui sua natureza genérica, ou da espécie:

A natureza é o corpo inorgânico do homem, a saber, a natureza enquanto ela mesma não é corpo humano. O homem vive da natureza significa: a natureza é o seu corpo, com o qual ele tem de ficar num processo contínuo para não morrer. Que a vida física e mental do homem está interconectada com a natureza não tem outro sentido senão que a natureza está interconectada consigo mesma, pois o homem é uma parte da natureza 5 .

Os produtos da atividade humana são natureza transmutada por meio do trabalho. Sob o capitalismo, todavia, a relação ser humano/natureza encontra-se distorcida, pois sob esse modo de produção a sociedade se organiza a partir de um sistema de propriedade primordialmente excludente, o que resulta em uma relação social de dominação e de exploração ${ }^{6}$.

A fruição do capital encontra seis barreiras, que se estabelecem e eventualmente impedem a acumulação e o crescimento necessário à taxa anual relativamente constante do capital, do contrário, formam-se crises. São elas: capital inicial sob a forma de dinheiro insuficiente; escassez de oferta de trabalho ou dificuldades políticas com esta; meios de

\footnotetext{
${ }^{2}$ O'CONNOR, Capitalism, Nature, Socialism: a theoretical introduction, p. 12.

3 LUKÁCS, Prolegômenos para uma ontologia do ser social, p. 67.

${ }^{4}$ MARX, O capital: crítica da economia política, 1(1), p. 65.

5 DUSSEL, La cuestión ecológica en Marx, p. 229.

${ }^{6}$ MARX, Manuscritos econômicos-filosóficos, p. 84.
} 
produção inadequados, incluindo os limites naturais; tecnologias e formas organizacionais inadequadas; resistências ou insuficiências no processo de trabalho; falta de demanda fundamentada em dinheiro para pagar no mercado. Assim, o modo e a taxa de produção de mercadorias, o processo de poluição que ocorre durante a produção, o consumo, a geração de resíduos -, considerando a necessária taxa de crescimento constante do capital, relacionam-se reciprocamente com os limites materiais da natureza. A disponibilidade de recursos naturais para a produção capitalista gera uma contradição entre a taxa de crescimento constante, que exige produção e consumo crescentes ou no mínimo estáveis por certo tempo. Mesmo quando há um limite à realização do capital (consumo), o capitalista tenta compensar na produção ou na manipulação no mercado de valores. Esse movimento pendular degrada a natureza seja no âmbito da extração de materiais, seja no âmbito da geração de resíduos/poluição. O problema intensifica-se quando são considerados os limites da natureza à produção e à manutenção das necessidades orgânicas dos seres humanos, dessa forma o "esgotamento e a degradação da terra e dos chamados recursos naturais não fazem mais sentido no longo prazo do que a destruição dos poderes coletivos do trabalho, pois ambos estão na raiz da produção de toda a riqueza"7.

O marxismo ecológico busca analisar dialeticamente os limites naturais, o trabalho alienado e a luta de classes derivadas do capitalismo como corresponsáveis pela pobreza e pela precarização do trabalho. Não cabe eleger apenas o modo de produção como genericamente responsável, pois a relação torna-se cada vez mais dramática na medida em que os recursos vão se tornando cada vez mais escassos e poluídos, o aquecimento global recrudesce, as florestas e hábitats são destruídos e fragmentados. Isso tenciona as relações sociais e o sistema de produção, pois as mercadorias tornam-se mais caras e os recursos naturais mais escassos e restritos a poucos detentores de poder monetário para explorá-los.

O conceito de metabolismo social é central e formalizador do marxismo ecológico. A noção de "falha metabólica" na interação entre o homem e a terra foi uma forma que Marx encontrou para explicar como a natureza engendra o metabolismo social e vice-versa. Reciprocamente, o capitalismo (como no caso do agronegócio, por exemplo) impede qualquer aplicação racional (ou sustentável) da ciência no manejo do solo, apesar de toda ciência e tecnologia, a recomposição cíclica do solo resulta inviável.

Trata-se do metabolismo como sinônimo de troca material relativa "à noção dos processos estruturados de crescimento e de decadência biológica englobados pelo termo metabolismo" 8 . Assim, é por meio do trabalho que o ser humano apropria-se da natureza, perfazendo o próprio processo de mediação metabólica com a natureza. Dessa forma:

Não é a unidade do ser humano vivo e ativo com as condições naturais, inorgânicas, do seu metabolismo com a natureza e, em consequência, a sua apropriação da natureza que precisa de explicação ou é resultado de um processo histórico, mas a separação entre essas condições inorgânicas da existência humana e essa existência ativa, uma separação que só está posta por completo na relação entre trabalho assalariado e capital ${ }^{9}$.

A ação regulatória da sociedade em relação à natureza depende da capacidade humana de afetar os processos naturais, porém, as condições não deixam de ser "impostas" pela natureza. Ou seja, a produção econômica depende da troca material derivada do fluxo circular ecológico. Os conceitos de metabolismo social e de falha metabólica permitem que se compreenda a relação entre as categorias de troca material e de ação regulatória impressa

7 7HARVEY, O enigma do capital e as crises do capitalismo, p. 66.

${ }^{8}$ FOSTER, A ecologia de Marx, p. 221.

9 MARX, O capital: crítica da economia política, 1(1), p. 648. 
pela sociedade, resumindo numa síntese dialética as condições naturais e a ação humana sobre mesmos processos ecológico-naturais.

A contradição fundamental entre o capital e a trabalho pode ser compreendida a partir apropriação privada dos meios de produção e da força de trabalho. Mas os limites dos recursos naturais, incluindo a subliminar capacidade de manutenção/recuperação da natureza, descrita como a resiliência dos ecossistemas, causa uma "segunda contradição que deriva da apropriação autodestrutiva pelo capitalismo e o uso que ele faz da força de trabalho, do espaço e da natureza exterior, ou seja, do meio ambiente"1o.

O resultado desta segunda contradição são os limites físicos com os quais o capital de esbarra, limites criados dentro de sua própria lógica produtiva. Combinado às novas tecnologias produtivas, o capital, considerado sua capacidade adaptativa, amplia a exploração dos bens naturais coletivos, ao mesmo tempo em que cria excedente de força de trabalho e novos mercados. Em um cenário de desenvolvimento desigual, as diferentes formas de contaminação e de escassez de recursos engendram-se com a precarização do trabalho e com a luta de classes. Deve-se considerar, portanto, a forma com que se concretiza o esgotamento dos recursos e a contaminação dos mesmos, já que seu esgotamento está relacionado com sua contaminação; esta relação encontra-se coordenada com a forma de desenvolvimento desigual historicamente concretizada no capitalismo.

O desenvolvimento desigual não se reduz, portanto, à concentração geográfica da produção industrial, ao comércio, à restrita concentração de renda em áreas urbanas e densamente povoadas; mas se estende à agricultura e à extração de matérias-primas em zonas subdesenvolvidas em que o "metabolismo básico" entre pessoas e natureza também foi perturbado ${ }^{11}$.

\section{Breve incursão na história ambiental da relação ser humano com os microorganismos}

Uma pessoa doente pode em poucas horas visitar diversos países. O desenvolvimento das tecnologias de transporte aéreo foi um dos fatores responsáveis pelo desenvolvimento de ramos da economia, como o turismo e o transporte de mercadorias em curto espaço de tempo. A circulação de capitais se acelera e o consumo pode aumentar, o que estimula a produção. Não se contava com este novo modelo de disseminação de doenças, a chamada globalização de microrganismos. Todavia, esses companheiros indesejados do Homo sapiens são bem antigos. O material genético do vírus ancestral da herpes foi detectado nos Australophitecus, no Homo erectus, no Homo ergaster, no Homo habilis e assim por diante. Os ancestrais da nossa espécie adquiriram parasitas de animais herbívoros que caçavam nas savanas da África, desde aproximadamente oito milhões de anos.

O papilonavírus humano (HPV), agente responsável pelo câncer de colo de útero, também foi encontrado em outros primatas, como o chimpanzé. No deserto do Atacama, Peru, múmias indígenas apresentavam sinais de tuberculose e o DNA da bactéria foi identificado no seu interior. O Homo sapiens partiu da África portando a bactéria da tuberculose e a transportou até suas rotas de migração.

A mudança dos hábitos nômades dos antigos caçadores-coletores marcou um importante estágio para a evolução humana. As populações passaram a se agregar em pequenas vilas, a cultivar seus alimentos e a domesticar animais. Surgiriam as cidades. O

${ }^{10}$ O'CONNOR, Capitalism, Nature, Socialism: a theoretical introduction, p. 13.

${ }^{11}$ O'CONNOR, Desarrollo desigual y combinado y crisis ecológica, p.15. 
adensamento populacional aliado ao contato direto com animais constitui o ambiente perfeito para o aumento das transmissões zoonóticas de microorganismos patogênicos.

Ambientes marginais de superfícies sazonalmente alagadas, como no delta do rio Nilo, ambientes propícios para a produção de alimentos, foram com o tempo se ampliando, para a produção de excedentes voltados ao escambo. O aumento da produção, ligado ao aumento da população e ao comércio levaram à ampliação das áreas irrigadas e alagadas agricultáveis. Represas e canais de irrigação surgiram nas proximidades dos vilarejos, o que levou à criação de ambientes favoráveis à proliferação de mosquitos transmissores de malária e de caramujos transmissores da esquistossomose. A malária acompanhou o aumento populacional desencadeado pela maior oferta de alimento vinda da agricultura. A análise de múmias comprova que a doença reinou pelo litoral do Mediterrâneo, da África, do Oriente Médio e da Ásia. A esquistossomose acompanhou a trajetória humana na África e na Ásia ${ }^{12}$.

A domesticação de animais levou à pecuária e o ser humano percebeu a necessidade de se locomover para comercializar seus excedentes. Um vírus mutante de animal (provavelmente o camelo) infectou o homem e deu origem ao vírus da varíola. A varíola, praga dos Hititas, provavelmente originou-se no Egito (1346 a.C), mas o primeiro surto epidêmico ocorreu durante a Guerra dos Elefantes, quando os etíopes cercaram Meca (568 d.C). O crescimento populacional tornou a varíola endêmica na Europa e Ásia, justamente a partir das rotas de mercadores, desde a Grécia e a Itália, com disseminações datadas nos séculos IV e V.

Em 1775, a partir de observações o trabalho de mulheres na extração de leite em vacas, o médico Edward Jenner notou que estas dificilmente apresentavam quadros clínicos típicos da varíola humana, mas que estavam infectadas com a varíola da vaca (Cowpox). Vinte anos depois, Jenner comprovou sua hipótese, inoculando um menino de oito anos com material retirado das lesões de cowpox de uma trabalhadora de ordenha de vacas. Posterirormente, percebeu que a criança apresentou imunização à varíola humana ${ }^{13}$.

Em 1918, ano em a primeira Grande Guerra chega ao fim, a Gripe Espanhola, que na verdade se espalhou desde o estado do Kansas (EUA), a partir de fazendas criadoras de suínos, disseminou a cepa A H1N1 no vírus Influenza por todo o mundo. A pandemia atingiu entre 25 a 30\% da população global, causando cerca de 40 milhões de mortes, sendo considerada a pandemia mais letal da história da humanidade ${ }^{14}$. $\mathrm{O}$ vírus $\mathrm{H}_{1} \mathrm{~N}_{1}$ afeta suínos, causando doença respiratória nesses animais e é capaz de infectar o homem por contato próximo. $\mathrm{O}$ vírus $\mathrm{H}_{1} \mathrm{~N}_{1}$ atual tem genes de suínos, aves e do homem, sendo uma variante agora de provocar a infecção inter-humanos ${ }^{15}$. O vírus Influenza também causou a Gripe Asiática (1957/1958), a qual teve início na China e se espalhou por países da Ásia, Europa, África, Caribe e América do Norte, causando 2 milhões de vítimas fatais. A Gripe de Hong Kong (1968-69), causada pelo vírus Influenza $\mathrm{H}_{3} \mathrm{~N}_{2}$ começou na China, propagando-se por outros países da Ásia, África, Europa e Estados Unidos, resultando em mais de 1 milhão de mortes.

A epidemia de SARS (Síndrome Respiratória Aguda Severa), foi provocada por outro tipo de vírus, o coronavírus, que infectou mais de 8 mil pessoas e matou cerca de 700 em 29

\footnotetext{
${ }_{12}$ UJVARI, A história da disseminação dos microorganismos, p.172-173.

13 TOLEDO JÚNIOR, História da varíola, p. 6o-62.

14 CAMPOS, Influenza, uma nova tsunami, p.1.

${ }^{15}$ GRECO; TUPINAMBÁS; FONSECA, Influenza A (H1N1): histórico, estado atual no Brasil e no mundo, perspectivas, p. 133 .
} 
países. Surgiu em novembro de 2002, apesar do só ter sido divulgada pela Organização Mundial de Saúde (OMS) no final de fevereiro de $2003^{16}$.

É razoável pensar que a realidade socioeconômica e cultural tem relação com os aspectos sanitários e ambientais que favorecem o surgimento e espraiamento de doenças, assim a qualidade e o acesso aos serviços públicos de saúde, as habitações e os ambientes de trabalho estão estreitamente vinculados ao nível socioeconômico de grupos sociais predominantes em setores diversificados do espaço urbano, o que certamente influi nas condições gerais de saúde pública.

O marxismo ecológico busca explicitar o modo como as sociedades produzem sua existência sob o capitalismo e estuda como ocorrem as relações entre produção, consumo e os impactos sobre os recursos naturais, incluindo a resiliência dos ecossistemas. Surtos epidêmicos e possivelmente pandemias, historicamente, surgem de transmissões zoonóticas que ocorrem de animais para o homem em ambientes marcados pela destruição derivada do modo de produção e organização social capitalista.

\section{O ambiente propício para uma pandemia}

Três aspectos da pandemia podem ser analisados com base no marxismo ecológico: o ambiente propício à gênese da transmissão zoonótica; as condições socioambientais que favorecem o contágio e a conjuntura socioeconômica que pode ser decisiva na efetividade do isolamento social. Dessa forma, as características biológicas do agente etiológico causador da doença devem ser estudadas no que se refere aos aspectos epidemiológicos, mas de forma relacionada com as condições socioambientais que permitem a transmissão zoonótica e o contágio entre seres humanos, o que pode levar a uma possível pandemia. Essa situação envolve trabalho precarizado em ambientes de trabalho insalubres (incluindo hospitais e unidades de atendimento básicos), o pauperismo e a degradação ambiental (no campo e nas cidades). Questiona-se: um sistema no qual sua manutenção depende de uma taxa crescente de produção-circulação-realização de mercadorias, sob quais condições sociais e sanitárias uma pandemia se concretizaria? As cidades, sob o capitalismo, não foram planejadas com base no critério da proteção à saúde pública. No campo, o agronegócio devasta florestas e expõe trabalhadores a animais selvagens que são verdadeiros reservatórios de patógenos.

Tanto no campo como na cidade os baixos salários impossibilitam que os trabalhadores adquiram habitações dignas à vida humana salutar. Desde meios de transporte público em péssimas condições, o que favorece a aglomeração em veículos lotados, até a falta de água constante em bairros pobres e periféricos; o pauperismo se amplia, a partir da exploração do trabalhador (extração de mais-valor), do desemprego e de salários reduzidos. Como esperar resultados significativos derivados do isolamento social, em casas superlotadas, com famílias sem condição nem para comprar sabão e com recorrente falta de água?

O coronavírus, causador da SARS, provavelmente foi transmitido por morcegos em mercados de animais e depois se deu a transmissão entre humanos. Ambientes naturais com relativo grau de degradação, como em fazendas onde ocorre fragmentação florestal, destruição de hábitats e diminuição da biodiversidade estão ligados a altos índices de transmissão zoonótica. Por outro lado, ecossistemas com alta biodiversidade se revelaram com baixa prevalência de contágio por patógenos provenientes do contato com animais. $\mathrm{Na}$ pecuária ocorre maior prevalência de trabalhadores agrícolas portadores do Influenza $\mathrm{H}_{1} \mathrm{~N}_{1}$,

${ }^{16}$ KLAJMAN, A gripe sob a ótica da história ecológica: um estudo comparativo entre as pandemias de 1918 e 2009 , p. 123. 
em se comparando trabalhadores rurais em áreas ambientalmente degradadas com a comunidade em geral. Esse tipo de exposição posteriormente ocasionou a pandemia de 2009; o mesmo padrão ocorreu com a hepatite E com a Influenza aviária, altamente patogênica ${ }^{17}$.

Hoje vemos o caos no SUS, com déficit de leitos de UTI, de respiradores e de equipamentos de proteção para os profissionais da saúde. Isso reflete a combinação entre má gestão do dinheiro público (incluindo prioridades excusas) e a enorme desigualdade na distribuição de renda. Na linha de frente, os técnicos de enfermagem, com seus péssimos salários, voltarão para suas humildes casas (em algum momento), sob quais condições de salubridade? A economia capitalista funciona como uma espiral de expansão e crescimento sem fim. Por conseguinte, reproduzo um importante questionamento: "como poderia o modelo econômico dominante, com sua legitimidade reduzida e sua saúde delicada, absorver e sobreviver aos impactos inevitáveis do que poderia se tornar uma pandemia?"18.

A falha metabólica com a natureza se expressa historicamente a partir da desvalorização das mercadorias que não podem ser vendidas, ou melhor, que não podem ser vendidas a tempo, conforme Marx ressaltou. Podemos, portanto, inferir que o desenvolvimento econômico desigual e o subdesenvolvimento aceleram a destruição da natureza. Esse tipo de desenvolvimento tende a intensificar a contaminação e a expansão da degradação dos ecossistemas do planeta, ao mesmo tempo em que (e justamente em função disso) intensifica a superexploração do trabalho sob sua forma assalariada, o que aumenta a pobreza, em especial em áreas subdesenvolvidas, o que, por sua vez, acelera a degradação da natureza. O resultado é uma espiral de destruição ecológica e humana que se autoperpetua ${ }^{19}$. Essa espiral tende a se ampliar espacialmente e a se intensificar ao longo do tempo, considerando a taxa de sobretrabalho, que se reflete no aumento da taxa de produção de mercadorias, demandando mais recursos naturais. O cenário fica mais precário, pois, mesmo em períodos de crises cíclicas do capital, em especial aquelas causadas pela superprodução e pelas quedas nas taxas de realização, a destruição socioambiental não necessariamente diminui; paradoxalmente, tende a aumentar, em função da pauperização crescente, a qual conduz, dentre outras coisas, a problemas crescentes de saúde pública.

\section{Referências}

CAMPOS, H. S. Influenza, uma nova tsunami. Pulmão, Rio de Janeiro, v. 14, n. 2, p. 104-108, 2005.

DUSSEL, E. La cuestión ecológica en Marx. In: Martínez, L. M (ORG.). Cultura y Naturaleza. Bogotá: Jardín Botánico de Bogotá, 2011.

FOSTER, J. B. Marxismo e ecologia: fontes comuns de uma grande transição. Lutas Sociais, São Paulo, v.19, n.35, p.8o-97, 2015.

GRECO, D. B; TUPINAMBÁS, U; FONSECA, M. Influenza A ( $\left.\mathrm{H}_{1} \mathrm{~N}_{1}\right)$ : histórico, estado atual no Brasil e no mundo, perspectivas. Revista de Medicina de Minas Gerais, v. 19, n. 2, p. 132139, 2009.

HARVEY, D. O enigma do capital: e as crises do capitalismo. São Paulo: Boitempo, 2011.

\footnotetext{
${ }^{17}$ JONES et al., Zoonosis emergence linked to agricultural intensification and environmental change, p. 8.401.

${ }^{18}$ HARVEY, Política anticapitalista em tempos de COVID-19, p. 14.

19 O'CONNOR, Desarrollo desigual y combinado y crisis ecológica, p.19.
} 
8 | Pandemia de Covid-19 e destruição da natureza: uma crítica baseada no marxismo ecológico

HARVEY, D. Política anticapitalista em tempos de COVID-19. In: DAVIS, M. et al. (Orgs.). Coronavirus e a luta de classes. Terra sem Amos: Brasil, 2020.

JONES, B. A. et al. Zoonosis emergence linked to agricultural intensification and environmental change. Proceedings of the natural academy os sciences of the USA (PNAS), v. 110, n. 21, p. 8399-8404, 2013.

KLAJMAN, C. A gripe sob a ótica da história ecológica: um estudo comparativo entre as pandemias de 1918 e 2009. História Revista, Goiânia, v. 20, n. 3, p. 118-137, 2015.

LUKÁCS, G. Prolegômenos para uma ontologia do ser social: questões de princípios para uma ontologia hoje tornada possível. São Paulo: Boitempo, 2010.

MARX, K. O capital: crítica da economia política. Livro I. v. 1. Rio de Janeiro: Civilização Brasileira, 2008.

MARX, K. Manuscritos econômicos-filosóficos. São Paulo: Boitempo, 2008.

MARX, K. Grundrisse: manuscritos econômicos de 1857-1858 - esboços da crítica da economia política. São Paulo: Boitempo, 2011.

O'CONNOR, J. Capitalism, nature, socialism: a theoretical introduction. Capitalism, Nature, Socialism, Londres, v. 1 n. 1, 1988.

O'CONNOR, J. Desarrollo desigual y combinado y crisis ecológica. Ambiente e Sociedade, Campinas, v.6, n.2, 2003.

TOLEDO JÚNIOR, A. C. de C. História da varíola. Revista de Medicina de Minas Gerais, v.15, n. 1, p. 58-65, 2005.

UJVARI, S. C. A história da disseminação dos microorganismos. Estudos avançados, São Paulo, v. 22, n. 6, p. 171-182, 2008. 